\title{
TANGO FATAL, SOBERBIO Y BRUTO: EL CORAJUDO COMPADRITO Y EL CULTO AL CUCHILLO EN BORGES'
}

1 La expresión tango fatal, soberbio y bruto, corresponde a los últimos versos del poema de Güiraldes titulado Tango, incluido en el Cencerro de Cristal, compilado y muchas veces referenciado por Borges.

\author{
Angie Arango
}




\title{
FATAL, ARROGANT AND ROUGH TANGO: THE BRAVE COMPADRITO AND THE CULT TO THE KNIFE IN BORGES
}

\author{
¿Dónde estará (repito) el malevaje \\ Que fundó en polvorientos callejones \\ La secta del cuchillo y el coraje?
}

(Borges, 2005, p.203)

El espíritu estático y dinámico del tango trasciende, llega al corazón de la obra de Borges y le permite encontrar filiaciones entre la historia musical, los rasgos epocales y su experiencia vital, incorporando series dicotómicas representacionales en su obra, así pampa-ciudad, guapo-compadrito, coraje-valentía y tango-muerte adquieren un lugar relevante en la labor estética y cartográfica del escritor argentino.

Jorge Luis Borges no vino al mundo a vivir sino a presenciar, a devorar imágenes, sonidos y conversaciones para convertirlas en literatura, porque no le sería posible compadrear desde su vida como bibliotecario y lector; pero sí reclamar otras vidas a través de sus geografías del viejo Buenos Aires. Un esfuerzo por transgredir la cerca que lo apartaba de un mundo y lo guardaba para otro, tal como nos dice Braceli (1998):

Trató, pero a lo sumo, fiel a su destino elegido, lo único que hizo fue tener un roce precario con ese mundo, beber con urgencia las anécdotas de algunas de sus gentes más pintorescas. Todo eso para transformarlo en literatura. (p. 95)

El Borges descrito allí es el bibliotecario de Alejandría, como lo llamó Abelardo Ramos ([1954]1999), haciendo gala de un desdén desmesurado por un Borges al que considera miembro de una casta parasitaria, un señorito púdico que "se burla entre dientes" (p.137) de los extremos límites urbanos y sus guapos característicos; sin embargo, nada más injusto con el artista que juzgarlo por su condición letrada aristócrata y no por su dominio estético. Su praxis escritural consiste en ficcionalizar, sin fustigar las maneras de vida halladas en las orillas, pues la censura llevaría a relatos de menosprecio sin posibilidad de dar cuenta de ambientes reales tanto en su Buenos Aires como en cualquier esquina de una calle latinoamericana1 donde se encuentran leyendas de combates como las que cuentan los viejos

$1 \quad$ Aunque expresara en entrevista con Andrés Openheimer y Jorge Lafforgue (1973) que no creía en la existencia de América Latina, por el contrario, consideraba que era una especie de pereza y comodidad.

\section{AUTORES}

\author{
Angie Arango \\ Docente de la Fundación Universitaria del Área Andina (sede Bogotá) \\ Profesional en Estudios literarios (c) \\ Universidad Autónoma de Bucaramanga
}

Recibido: 4 de junio 2018

Aprobado: 15 de octubre 2018

Correo electrónico: angieandreaarango@gmail.com 
bonaerenses sobre el otrora café Hansen en Palermo y el Americano en la calle Carabelas.

La ciudad que Borges describe no es la misma que había dejado al irse a estudiar a Ginebra y vivir tres años en España; la diferencia de siete primaveras había producido en él una fuerte añoranza y un deseo irresistible de captar la esencia de Buenos Aires tal como la había rememorado con todas sus asociaciones románticas; pues, consideraba como únicos vestigios auténticos de la ciudad los arrabales y las viejas calles constituyentes de un conjunto de elementos que físicamente formaban un arraigo temporal a la pampa.

El recorrido vital de Borges ([1923] 2007) se despliega hacia lo urbano. Desde los "arrabales desmantelados del mundo" (p. 41), "reflejo de nuestro tedio" (p. 35), el autor se asienta literariamente en la ciudad; ese organismo artificial y acuciante llamado dos veces Buenos Aires2, la remota Gran Aldea cuyas "calles recuerdan / que fueron campo un día" (p. 49) y que en el colofón del siglo XIX se metamorfoseaba en una moderna metrópoli.

El escritor argentino estaba creando a partir de su primer libro, Fervor de Buenos Aires de 1923, una estética de la orilla: esa zona entre indefinible ciudad y la pampa, que representa el vecindario, el arrabal; y eso fue, ya no un barrio fuera de unidades territoriales legales, sino la invención de un lugar literario, su posibilidad para anatematizar las ideas fundacionales de la argentinidad.

Los arrabales y los suburbios del sur de Buenos Aires son elementos fronterizos que facilitarían al escritor el

$2 \quad$ La Ciudad de Buenos Aires tuvo dos fundaciones. La primera en 1536 por Pedro de Mendoza (destruida en 1541 por los propios habitantes a raíz de las constantes amenazas de los nativos), y la segunda en 1580 por Juan de Garay. En ambas ocasiones perteneció al Virreinato del Perú del Imperio Español. pasaje a su mundo de lo irreal, así lo vemos en el poema ${ }^{3}$ Cercanías ([1923] 2007) cuando habla de "los sitios/ donde se desparrama la ternura/y el corazón está consigo mismo [...] en arrabales hechos de acallamiento y sosiego" (Borges, 2007, p. 66); asimismo, en poemas como Mi vida entera ([1925] 2007) encontramos alusiones a los horizontes de vida en los suburbios o también en Versos de catorce ([1925] 2007) donde continúa la elaboración simbólica de los elementos mencionados y explora un espacio imposible que es presentado por medio de un artilugio narrativo, desde el cual Borges recurre a la cotidianidad en tanto colección de objetos y lugares que su memoria sitúa y recorre: los almacenes, las esquinas rosadas ${ }^{4}$, los conventillos del centro, las calles desconocidas y los patios.

Una idea generalizada se cierne sobre el arrabal ubicado en los límites geográficos de la ciudad porteña cerca de las casas malas (Borges, 2016); sin embargo, es justo decir que su lugar es una zona incierta entre urbe y pampa, es decir que, más que referir a los barrios orilleros, es el alma transformadora de la ciudad, la grilla de unión entre tiempos y tradiciones.

Borges es un cartógrafo de evocaciones y lugares $y$, en honor a ello, se interesó en la vida de los arrabales de Buenos Aires para acercarse a su lenguaje (el lunfardo)-, a su música -(la milonga y el tango)- y a uno de sus habitantes: el guapo y su reflejo distorsionado, el compadrito, así como a una de sus performatividades, el cuchillero, aquel hombre armado siempre por

3

Aunque el tema del arrabal es más predominante en su poesía, en sus cuentos también aparecerán de manera recurrente.

$4 \quad$ Aquel color, nos cuenta Borges (1968), era el color característico en las construcciones de los barrios orilleros hacia 1895. 
un facón ${ }^{5}$. Aunque jamás presenció, según escribe Monegal (1987), un duelo a cuchillazos en los arrabales (pero sí observó a un hombre ultimar a otro hacia 1934, año en el que aparecerá Hombre de la esquina rosada) escribiría textos del más variado talante: crónicas, ensayos, poemas, cuentos, que considerados en su conjunto pueden leerse como una épica de la compadrada (posteriormente consagró sus esfuerzos a la literatura fantástica, al género policial, a la divagación metafísica, entre otras manifestaciones de su obra), que refiere un tipo temido y alabado, reconocido por ser el patrón del coraje. Sin embargo, la escritura borgeana, más allá de construir apologías a ese arrojo, desenmascara a este mito vivo urbano y lo acerca a la cobardía, de tal suerte que desdibuja los límites y los personajes del que se convirtiera en un arquetipo del arrabal porteño.

Si bien "el guapo era un compadre - ambas voces son sinónimos- y aceptaba ese apelativo, le disgustaba el remoquete diminutivo de <<compadrito>>" (Salas, 1997, p. 77), personaje frecuentemente confundido con el guapo, pero que en realidad es la personificación del arrabalero fanfarrón, aquel corajudo espectacular, vanidoso, que no obstante exhibir un aire retador, se delata como jactancioso, tal como recuerda Manuel Gil de Oto (1968) cuando describe a través del poema El compadre a un hombre de "condición cobarde que tapa su lengua agresiva" (p.65); quizás entreveramos la génesis de este personaje en el Miles glorious del dramaturgo latino Plauto (1996), y el compadrito de facón sea un vástago de ese embrión, una épica invertida. Recordemos como ejemplo que Hombre de la esquina Rosada presenta al guapo falseado

$5 \quad$ Suele llamarse facón a la variedad de cuchillos criollos que solían cargar los gauchos y sobre cuya extensión se asocia la del machete. Sin embargo, el facón también podía tener otras dimensiones que configuran tipos de este cuchillo: facón verijero, cuchillo macho, daga y puñal, este último será la extensión de la mano del guapo o compadre. del barrio rehuyendo del combate y a un asesino bajo el signo del ocultamiento, tal y como se puede leer en la secuencia final del cuento:

a. la aparición (teatral) de la Lujanera y Real, herido de muerte dentro de la misma secuencia

b. la Lujanera relata el ataque de un desconocido

\section{c. Real muere}

d. la Lujanera es acusada por todos y defendida por el narrador, agregándose observaciones sobre la muerte

e. Ilega la policía y los hombres hacen desaparecer el cuerpo, despojándolo antes de sus pertenencias

f. el narrador vuelve al rancho, mira el puñal para comprobar que "no quedaba ni un rastrito de sangre" (Borges, 2007, p. 396).

El compadrito reproduce e interviene las actividades del compadre, con un cariz más adusto. No era un compadre, pues apenas compadreaba; hacía alardes y ostentoso se movía entre las noches alcoholizadas por la caña, licor dulce y entrador, espíritu líquido para el fandango y la pelea quizás en algún peringundín. En sus conductas, gestos y actitudes, estos personajes, habitantes del suburbio, presentan fuertes signos de arrojo, pero a su vez circunspección y nobleza.

El arrabal genera al compadrito, y este es la personificación en diminutivo del compadre, aquel que entra en contacto con la civilización urbana desde abajo "como arreador, conductor de carretas, carnicero, resero" (Sáenz; 1968, p.8). Es el gaucho del poblado, en cuyas esquinas y almacenes Borges buscará su fantasma, el héroe anhelado. Borges buscará allí, en esas calles periféricas, reencarnación de la pampa y escenario 
propicio para la reelaboración del coraje, en un Buenos Aires de topografía de tiempo y espacio conjugados desde la ambigüedad de un lugar que no solo engendraba suburbios, sino también, un personaje híbrido entre compadre y gaucho.

Así como Leopoldo Lugones (1911) hace más de cien años exhibió la figura del gaucho, transfigurado de enemigo civilizatorio al arquetipo de la argentinidad, Jorge Francisco Isidoro Luis Borges Acevedo, años después en un ensayo biográfico sobre Evaristo Carriego ([1930]2007), posicionó a compadritos y cuchilleros en tanto figuras que emergen al igual que el gaucho, como un referente equivalente al Martín Fierro ( [1872] 2015) y la necesidad de erigir su historia como una épica, pues en opinión del escritor (Citado por Ramos [1954]1999), el personaje de José Hernández no es más que un "cuchillero individual de 1870 [...], un malvado o ,como dijo festivamente Macedonio Fernández, un siciliano vengativo"(135), interpretación que le permite denostar la idea misma de la patria.

Aquellos personajes de la sociedad porteña de finales del siglo XIX e inicios del XX, fueron una visita recibida por un Borges testigo de la tradición gauchesca, temática ligada a la genealogía familiar y cultural de la Argentina, antecedente migratorio de la urbanización ciudadana, protagonista de una narrativa que traza un viaje desde los confines de la pampa hasta los patios de los arrabales porteños. Será sobre aquel "individuo jactancioso, falso, provocativo y traidor, que usa un lenguaje especial y maneras afectadas" (Segovia, 1911, p. 42) que el escritor bonaerense dirá:

Los compadritos vinieron a mi vida y a mi obra con los malevos y los arrabales, un poco por curiosidad y otro poco porque en la religión que ellos habían construido -la del coraje- yo encontraba cosas que le faltaban a mis días: el arrojo físico, la valentía, todo eso. (Borges, 1979, P. 130)
Cuando Borges se interesó por estos personajes, los sobrevivientes eran sombras del pasado, cuyas hazañas iban de boca en boca por el barrio forjando mito y leyenda; tal es el caso de Juan Muraña, hombre letal, paseador consagrado en la obra del escritor, ya sea en los poemas Milonga de don $\mathrm{Ni}$ canor Paredes (1965), Alusión a una sombra de mil ochocientos noventa y tantos (1960), Milonga de Juan Muraña (1981), en El informe de Brodie (1970), o ya en uno de los episodios en Evaristo Carriego ([1930]1955), donde narra:

Juan Muraña, carrero y cuchillero en el que convergen todos los cuentos de coraje que andan por las orillas del Norte. Esa primera versión era simple. Un hombre de los Corrales o de Barracas, sabedor de la fama de Juan Muraña (a quien no ha visto nunca), viene a pelearlo desde su suburbio del sur; lo provoca en un almacén, los dos salen a pelear a la calle; se hieren, Muraña, al fin, lo marca y le dice: -Te dejo con vida para que volvás a buscarme-. (Borges, p.166)

Allí, donde lo orillero porteño genera una atmosfera de ilusión, a través del personaje de Muraña, es posible anunciar una filiación con estos personajes y eventos conocidos, mas no experimentados por nuestro gentleman bonaerense, quien no solo mostró interés por los valientes, sino que dispuso un desplazamiento desde los personajes de la épica orillera hacia la construcción de un instrumento-sujeto, al presentar cuchillos que pelean; ya no en tanto instrumentos sino como seres volitivos, de tal forma que los guapos se transforman en la herramienta. En la literatura borgeana, el argentino, concretamente el compadrito, el gaucho, vive aferrado a la hoja de la barbarie: el cuchillo, ese es su estilo de vida.

El sortilegio que describe y construye el escritor (Borges,1932) en estos objetos puntiagudos, quizás 
pueda ser comprendida desde su excursión por el campo antropológico cuando postula el vínculo inevitable entre aparentes entes distantes (hombrecuchillo), en cuya ficcionalización narrativa se origina un nuevo orden; pues, aunque el facón sea un artefacto que crea el hombre para sí mismo, una transferencia del calor del cuerpo del hombre al cuchillo distorsiona los roles en tanto que este va unido al cuerpo (a diferencia del machete o la espada), actuando según las cualidades y sentimiento de su dueño, pero ¿quién gobierna a quién? la corta dimensión de su hoja, representa la predominancia del instinto que transmite.

Simbólicamente, el cuchillo "está asociado a las ideas de venganza y muerte, pero también a las de sacrificio" (Cirlot, 1992, p. 159); así como puede ser un instrumento para garantizar la supervivencia alimenticia por el consumo de carne (empleado para capar, desangrar, cortar y despellejar un bovino, de manera rudimentaria), también puede observarse un uso asociado a la muerte del prójimo, destino aparentemente inevitable en las historias escritas por Borges al respecto.

En la obra de Borges los cuchillos son la materialización de un objeto arquetípico, que adquiere una dimensión simbólica al cruzar los límites temporales: el cuchillo en manos de Juan Dahlmann, el Mentao y el Chileno, Juan Muraña, los hermanos Iberra, o el mismo Jacinto Chiclana ${ }^{6}$.

Respecto al emblema del cuchillo, recordemos que los símbolos son la clave que propone Borges como un intento para comprender la existencia infausta del hombre. Si bien, siguiendo a Alazraki (1983), el cuchillero es una expresión exacerbada de coraje,

$6 \quad$ En su orden, los personajes mencionados corresponden a los relatos de El sur ([1953]2013), Hombres pelearon ([1928]2007), los poemas Milonga de Juan Muraña (1981), Milonga de dos hermanos (1965), y Milonga de Jacinto Chiclana (1965). configurado como una ley que ordena estar siempre dispuesto a matar y a morir, en la escritura borgeana encontramos que el cuchillo ya no es un instrumento para imponer el coraje (pues ya vimos que delata la cobardía de los personajes), por el contrario, en relatos como El encuentro (1970) y El puñal (1998) son los cuchillos que-quienes se baten en duelo, presienten, viven y quieren verter sangre.

El compadrito: "el plebeyo de las ciudades y del indefinido arrabal” (Borges, 1968, p.7), así como el gaucho lo fue de la llanur, es el malevo orillero de los tangos. Diestros con el cuchillo, hombres atravesados, cultores ingenuos del mítico Ares, agasajado recurrente de las pampas gauchescas a los planos del arrabal, a través de estos fulanos fachendosos, que, entre corridas, ochos, firuletes y un do, un do... paso atrás, como si se tratara de un baile de tango, exhibían formas corporales vinculadas a la pelea diestra con guillotina de mano.

Cabe recordar que el tango "se bailaba por la honda fruición de bailar, pero se bailaba peleando. La rivalidad entre los danzantes, la pugna entre los barrios, consumían atención y requerían cuidado" (Salas, 1997, p. 27); era entonces un baile de hombres, bailado entre hombres, que terminó por constituir -más allá de la danza y la canción- un sistema filosófico, a manera de eterna reflexión sobre el tiempo - perdido según un gran volumen de letras y tonadas-, los fantasmas y el destino, todos estos, temas borgianos.

El tango y la muerte, declara el escritor (Borges, 2016), es el germen de su cuento Hombre de la esquina rosada (mencionado previamente en este texto) que relata la historia de una noche en el "salón de Julia" en pleno Barrio Santa Rita, cuando Francisco Real, apodado El Corralero, dando un empellón a la puerta, ingresa con actitud provocativa para buscar a Rosendo Juárez, conocido como El Pegador, el guapo del barrio. El Corralero desafía a Rosendo, 
generando expectación en los visitantes del lugar; aguarda el duelo, pero El Pegador se niega a pelear. He aquí que Borges anula el valor, pues la cobardía, vista con desprecio en muchas culturas, transfigura el coraje en signo narrativo que crea conciencia histórica en Rosendo, toda vez que no presenta su acción como declinación de la prudencia, sino que delata la práctica del cuchillo en tanto filosofía del absurdo, rompiendo un principio universal de las orillas donde el coraje se aleja de la virtud y se coliga con el exceso personificado en el corajudo fanfarrón.

El tango que surge oscuramente de la milonga, quizás filiado a la Habanera por allá en 1880 (Salas, 1997), se impone en el cuento desde su forma dicharachera y valerosa que presenta el ritual de la fatalidad: Hombre de la esquina rosada es un tango trágico y letal sobre la perdida, en él un hombre pierde fama, mujer y vida bajo la noche.

El baile y la música funcionan como fuerzas autónomas que contribuyen a quitar (pero no impedir) realidad a los acontecimientos, a situarlos en una atmósfera literaria cerrada: así se dice que "el tango hacía su voluntad con nosotros y nos perdía y nos ordenaba y nos volvía a encontrar" (Borges, 2007, p, 390), que Real y la Lujanera bailaban "como en la marejada del tango, como si los perdiera el tango" (Borges, 2007, p, 390) y que "en esa diversión estaban los hombres, como en un sueño" (Borges, 2007, p, 392). Todas estas expresiones de la teatralidad se proyectan multidimensionalmente: desde la construcción de los espacios de la acción (los almacenes, la calle, el arroyo, la esquina), la dimensión temporal unitaria del relato (la noche, un tango), la mecánica con la que se desenvuelven los personajes (la danza brava y cobarde) y hasta su modo de comunicar (ingresar al lunfardo sin caer en argentinismos excesivos); la escritura de Borges y los recorridos construidos en su escritura reivindican un estatuto ficcional, to- mando como engranajes de su máquina creadora la idealidad envolvente como cualidad sobresaliente.

\section{REFERENCIAS}

Alazraki, J. (1983). Lo esencial argentino, en la prosa narrativa de Jorge Luis Borges. Madrid: Editorial Gredos.

Borges, J. L (1923) Fervor de Buenos Aires. En Borges, J, L (2007) Obras completas 1923-1949. Argentina. Emecé editores

Borges, J. L (1925) Luna de enfrente. En Borges, J, L (2007) Obras completas 1923-1949. Argentina. Emecé editores

Borges, J. L (1928) El idioma de los argentinos. En Borges, J, L (2007) Obras completas 1923-1949. Argentina. Emecé editores

Borges, J. L (1930) Evaristo Carriego. En Borges, J, L (2007) Obras completas 1923-1949. Argentina. Emecé editores

Borges, J. (1930). "Evaristo Carriego". En: Borges, J. (1955). Obras completas, $2^{\mathrm{a}}$. Ed. Buenos Aires: Emecé editores

Borges, J. (1932) El arte narrativo y la magia. Revista Sur. Año II, pp. 172-179 Estados Unidos. Vintage español.

Borges, J. (1965) Para las seis cuerdas. Argentina. Emecé editores.

Borges, J, L; Bullrich, S (comp.) (1968) El compadrito: su destino, sus barrios, su música. Buenos Aires: Compañía General Fabril Editora

Borges, J. L (1970) El informe de Brodie. Madrid. Alianza Editorial. 
Borges, J. L (1981) La cifra. Argentina. Emecé editores.

Borges, J. L (1998) El puñal. En Nueva antología personal. México D.F. Siglo XXI.

Borges, J. L (2005) El otro, el mismo. Argentina. Emecé editores.

Borges, J. L (2013) Ficciones. Reino Unido. Editorial Bloomsbury.

Borges, J.L (2016) El tango. Argentina: Lumen.

Braceli. R (1998) Don Borges, saque su cuchillo porque he venido a matarlo. Argentina. Ediciones Galerna.

Cirlot, J, E (1992) Diccionario de símbolos. Barcelona. Editorial Labor.

Gil de Oto, M (1968) El compadre. En Borges, J, L; BuIlrich, S (comp.) (1968) El compadrito: su destino, sus barrios, su música. Buenos Aires: Compañía General Fabril Editora, pp. 65-67

Hernández, J (2015) Martín Fierro. España. Ediciones Cátedra.

Lugones, L (1911) Historia de Sarmiento. Buenos Aires. Otero y Co. Impresores.

Mactas, M (1979) Entrevista a Borges. En Braceli. R (1998) Don Borges, saque su cuchillo porque he venido a matarlo. Argentina. Ediciones Galerna.

Monegal Rodríguez, E (1987) Borges una biografía intelectual. México. FCE.

Oppenheimer, A; Laforgue, J (1973) El pensamiento vivo de Jorge Luis Borges. Revista Siete Días. No. 310 , pp. 55 a 59.
Ramos, J, A (1954) Borges, Bibliotecario de Alejandría. En Lafforgue, M. E (comp.)

(1999) Antiborges. Buenos Aires. Ediciones B, pp. $127-140$

Salas, H (1997) El tango (tomo I) Buenos Aires, Editorial Planeta

Segovia, L (1911) Diccionario de Argentinismos, neologismos, y barbarismos. Buenos Aires. Comisión Nacional del Centenario BsAs 1911

Tito Macio Plauto (1996) El militar fanfarrón. España. Editorial Gredos. 